\title{
Radiological evidence of sinus infection in patients with multiple sclerosis
}

\author{
C N Martyn, I Colquhoun
}

\begin{abstract}
The prevalence of radiological criteria of chronic sinus infection was compared in 42 cases of clinically definite or laboratory supported definite multiple sclerosis and 84 controls. No increase in relative risk of multiple sclerosis associated with the presence of chronic sinus infection was observed (odds ratio $1 \cdot 2,95 \%$ CI $0 \cdot 5$ to $3 \cdot 1)$. The maxillary sinus was infected more often than the other paranasal sinuses but there was no difference in the distribution of infection within the sinuses between cases and controls. These results do not confirm an earlier report of an association between chronic sinus infection and multiple sclerosis.
\end{abstract}

A case control study, based on general practice records, produced evidence of a strong association between multiple sclerosis and infection of the paranasal air sinuses. ${ }^{1}$ The authors of the report later advanced the ingenious hypothesis that multiple sclerosis might be the result of direct bacterial invasion of the central nervous system by motile organisms, such as spirochaetes, that gained entry to the central nervous system through defects in the bony walls surrounding the sphenoid air sinus. ${ }^{2}$ Although these ideas stimulated much comment, the validity of the study was questioned. The most serious criticisms concerned inaccuracies in the clinical diagnosis of sinusitis in general practice, the difficulty of avoiding bias in the retrospective ascertainment of episodes of infection from practice records and selection of the control groups. ${ }^{34}$

We have carried out a case-control study to investigate the possible association between multiple sclerosis and sinusitis using radiological rather than clinical criteria to establish a diagnosis of sinus disease.

MRC Environmental
Epidemiology Unit,
Southampton General
Hospital,
Southampton
CN Martyn
Department of
Radiology, Charing
Cross Hospital,
London, UK
I Colquhoun
Correspondence to:
Dr Martyn
Received 18 October
and in final revised form
8 March 1991 .
Accepted 26 March 1991

\section{Patients and methods}

All incident cases of multiple sclerosis seen at the Wessex Neurological Centre between 1966-70 were identified from a diagnostic index. During this period before CT scanning was widely available, investigations carried out on patients with symptoms suggesting neurological disease frequently included routine plain radiographs of the skull. The hospital records of these cases were examined and they were included in the study if a diagnosis of clinically definite or laboratory supported definite multiple sclerosis ${ }^{5}$ could be established and if both lateral and anteroposterior radiographs of the skull had been taken. Most of these patients had been followed up for many years and diagnostic certainty was high.

The radiology department of the Wessex Neurological Centre maintains a patient index filed alphabetically by surname. Two controls for each case were selected by searching forward from the entry of the case for the first two entries of the same sex and within the same five year age band (for example, 30-34, 35-39, 4044) who had also had skull radiographs taken. Controls were excluded if the reason for the radiograph was a complaint of headache or if they had been referred from an ENT department. This was necessary to prevent the sample being biased by patients referred because of sinus disease. To avoid unblinding the radiologist to the diagnosis, controls were also excluded if their skull radiographs showed evidence of craniotomy or other neurosurgical procedure.

The lateral and anteroposterior skull radiograph of each case and control were presented to a neuroradiologist. Neither the radiologist nor the person presenting the films to him knew whether the films belonged to a case or a control. The radiologist was asked: 1) If there was evidence of past or present sinus infection; 2) Which sinus was affected (if the answer to question 1 was positive); 3) To assess the size of the sphenoid sinus. Criteria for diagnosing sinus infection were: presence of a fluid level within the sinus, opacification of the sinus or thickening of the mucosa lining the sinus. The sphenoid sinus was graded as small if pneumatisation did not extend posteriorly beyond the middle of the pituitary fossa, medium in size if it extended beyond the middle of the fossa but not into the dorsum sellae and large if the dorsum sellae was pneumatised.

We estimated within-observer variation by selecting at random 33 pairs of lateral and anteroposterior skull radiographs from the series of cases and controls and showing them to the same observer (IC) on two occasions eight weeks apart. His evaluations were identical in $76 \%$ of cases. All assessments of radiographs reported in this study were made by one person so that between-observer variation is eliminated. However, to be sure that his assessments were not especially idiosyncratic, 54 pairs of radiographs were viewed independently by a second radiologist. Their diagnosis of sinus disease was identical in $72 \%$ of cases. 
Table 1. Frequency of sinusitis in 42 matched sets of cases and two controls

\begin{tabular}{llc}
\hline & $\begin{array}{l}\text { Number of controls } \\
\text { sinusitis }+\end{array}$ & Frequency \\
\hline Case sinusitis + & neither & 4 \\
& one & 11 \\
both & 9 \\
Case sinusitis - & neither & 5 \\
& one & 10 \\
& both & 3 \\
\hline
\end{tabular}

Statistical analysis was carried out using conditional logistical regression techniques to take into account the matched nature of the design of the study. The odds ratio (that is, the ratio of the odds of cases being exposed to the odds of controls being exposed) has been used as an estimator of relative risk.

\section{Results}

Forty two cases (16 men, 26 women) of clinically definite multiple sclerosis were included. Their mean age at the time skull radiographs were taken was 39 years (range: 18-61 years).

The prevalence of radiologically diagnosed sinusitis was $55 \%$ in both cases and controls. The relative risk of multiple sclerosis associated with sinusitis was $1 \cdot 2 \quad(95 \%$ confidence interval: $0 \cdot 5$ to $3 \cdot 1)$. The data for matched sets of case and two controls is summarised in table 1.

Analysis of sub-groups showed no consistent tendency for sinusitis to be more common in one sex or in any particular age group. Radiological signs of sinusitis were most frequent in the maxillary sinus but the distribution of radiological signs of sinusitis between the different sinuses did not differ between cases and controls. The sphenoidal air sinus tended to be larger in cases than in controls but the differences were not statistically significant. These results are shown in table 2 .

We analysed the results by month in which

Table 2 Odds ratios for the association of multiple sclerosis with radiological signs of infection in the para-nasal air sinuses

\begin{tabular}{|c|c|c|c|}
\hline & & $O R$ & $95 \% C I$ \\
\hline $\begin{array}{l}\text { Infection in any sinus } \\
\text { maxillary } \\
\text { ethmoid } \\
\text { frontal } \\
\text { sphenoid }\end{array}$ & & $\begin{array}{l}1.2 \\
1.5 \\
0.7 \\
1.0 \\
1.0\end{array}$ & $\begin{array}{l}0.5 \text { to } 3.1 \\
0.7 \text { to } 3.3 \\
0.3 \text { to } 1.9 \\
0.2 \text { to } 6.4 \\
0.3 \text { to } 4.0\end{array}$ \\
\hline $\begin{array}{l}\text { Infection in any sinus } \\
\text { Infection in any sinus }\end{array}$ & $\begin{array}{l}\text { (women only) } \\
\text { (men only) }\end{array}$ & $\begin{array}{l}1.3 \\
1.0\end{array}$ & $\begin{array}{l}0.5 \text { to } 3.4 \\
0.3 \text { to } 3.7\end{array}$ \\
\hline $\begin{array}{l}\text { Infection in any sinus } \\
\text { Infection in any sinus }\end{array}$ & $\begin{array}{l}\text { (aged } \leq 34 \text { years) } \\
\text { (aged } \geq 35 \text { years) }\end{array}$ & $\begin{array}{l}0.7 \\
1.5\end{array}$ & $\begin{array}{l}0.2 \text { to } 2.7 \\
0.6 \text { to } 4.0\end{array}$ \\
\hline $\begin{array}{l}\text { Size of sphenoid sinus } \\
\text { Size of sphenoid sinus }\end{array}$ & $\begin{array}{l}\text { small + medium } \\
\text { large }\end{array}$ & $\begin{array}{l}1 \\
2 \cdot 2\end{array}$ & 0.9 to 5.2 \\
\hline
\end{tabular}

the radiographs were taken expecting to find an excess of sinusitis in the winter months. No statistically significant seasonal trends were found.

\section{Discussion}

We found no evidence of an increased prevalence of sinusitis in cases of multiple sclerosis when compared with controls. Our estimate of the relative risk of multiple sclerosis in patients with radiological evidence of sinusitis is not sufficiently precise to exclude the possibility that sinusitis confers a small increase of risk - the confidence interval around the estimate of relative risk extended from 0.5 to $3 \cdot 1$-but it provides no confirmation of the strong association between the two conditions that has previously been reported.

The diagnosis of chronic sinus infection is notoriously difficult. Plain radiographs of the skull tend to overdiagnose infection because they discriminate poorly between allergic and infective causes for sinusitis. ${ }^{67}$ Definitive diagnosis requires CT or MRI scanning or antroscopy. Nonetheless, radiological criteria provide a more specific way of recognising sinus infection than reliance on clinical signs and symptoms. ${ }^{8}$ At the very least, the results of this study suggest that the apparent association between multiple sclerosis and what is diagnosed in general practice as sinusitis, cannot simply be explained by a higher prevalence of bacterial infection of the paranasal air sinuses in patients with multiple sclerosis.

We are grateful to Mrs Clare Harris for her help with the organisation of this study and to Mrs Gill Strange who prepared the manuscript. We are also indebted to Dr E H Burrows and Dr $\mathrm{P}$ Cook who allowed us to use the records and X-rays of the neuroradiology department of the Wessex Neurological Centre.

1 Gay D, Dick G, Upton G. Multiple sclerosis associated with sinusitis: case-control study in general practice. Lancet 1986;i:815-19.

2 Gay D, Dick G. Is multiple sclerosis caused by an oral spirochaete? Lancet 1986;ii:75-77.

3 Joseph HT, O'Donoghue GM. Multiple sclerosis and sinusitis. Lancet 1986;i:1159.

sinusitis. Lancet $1986 ; 1: 1159$.
Porter AMW. Multiple sclerosis associated with sinusitis. Lancet 1986;i:1096-7.

5 Poser CM, Paty DW, Scheinberg L, et al. New diagnostic criteria for multiple sclerosis: guidelines for research protocols. Ann Neurol 1983;13:227-31.

6 Pfleiderer AG, Croft CB, Lloyd GAS. Antroscopy: its place in clinical practice. A comparison of antroscopic finding with radiographic appearances of the maxillary sinus. Clin Otolaryngol 1986;11:455-61.

7 Axelsson A, Grebelius N, Chidekel N, Jensen C. The correlation between radiological examination and the irrigation findings in maxillary sinusitis. Acta Otolaryngol 1970;69:302-6.

8 Hinde RT. A review of the diagnostic problem in one hundred cases of chronic maxillary sinusitis. $J$ Laryngol and Otol 1950;64:687. 